\title{
An Empirical Study on Factors Influencing the Competitiveness of Service Industry in Guangxi
}

\author{
Xin Zhu \\ Department of Management, Guangxi University of Science and Technology, Liuzhou, P.R.China \\ 5266736@qq.com
}

\begin{abstract}
Keywords: Affecting factors; Unit root test; Cointegration analysis; Error Correction Model
Abstract: This paper chooses the level of economic development, income level, demographic factor, urbanization level, industrialization level, openness, government function, human resources as the affecting factors which influence the competitiveness of Guangxi service industry by taking full account of the previous research experience and the actual situation of the development of service industry. This paper selects a total of 13 years' data in the range of 2000 to 2012 and uses cointegration analysis and error correction model to analyze the short-term and long-term relationships between dependent and independent variables. Then finding out the main factors that influence the competitiveness of service industry, respectively are the per capita GDP, urbanization level, openness and government function.
\end{abstract}

\section{Introduction}

In the 21st century, great changes have taken place in China's service industry. As one of the three industries, the service industry's status is rising in the national economy. The service industry has gradually become an important driving force for economic development. Under the general trend of the world economy which changes from the industrial economy to the service economy, the development of China's service industry is being taken more seriously. Guangxi service industry has made great progress in this trend. "Statistical Communique of 2013 national economic and social development of the Guangxi Zhuang Autonomous Region” statistics that in 2013 the tertiary industry as a service industry added value is $\mathbf{5 1 7 . 1 3 9}$ billion yuan, indicating an increase of 10.2 percent; the region's annual GDP is 1.4378 trillion yuan and the tertiary industry added value accounts for 36 percent in the region's annual GDP. All listed data shows that the service industry in Guangxi is growing, the level and competitiveness enhance unceasingly, which has become one of the important areas of the region's economic development. However, the overall competitiveness of the service industry is weak than other parts of our country. There exist some problems, such as low-level services, backward technology, low efficiency etc. Therefore, this paper is in order to explore the reason of these problems and find out the various influencing factors of the competitiveness of service industry based on the previous literature.

\section{Variable Selection and Model Building}

\subsection{Variable Selection}

This paper summarizes others' research and actual situation of economy and takes the data availability into account to decide to adopt one dependent variable and eight independent variables in order to study the level of service development.

\subsubsection{Dependent Variable}

The development level of service industry. The service industry added value can embody the regional service industry development best. So using the proportion of service added value accounted for the GDP to explain the development level because of units. This dependent variable is shown in SGDPR. 


\subsubsection{Independent Variable}

Level of economic development. In this paper, it can be measured in per capita GDP and expressed as PGDP ${ }^{[1]}$.

Income level. In this paper, it can be measured in per capita annual disposable income of urban households and expressed as PADI. $\mathrm{PD}^{[2]}$

Demographic factor. In this paper, it can be measured in population density and expressed as

Urbanization level. In this paper, it can be measured in non-agriculture ratio and expressed as NAR.

Industrialization level. In this paper, it can be measured in the proportion of industry added value accounted for the GDP and expressed as IGDPR.

Openness. In this paper, it can be measured in total import \& export ratio and expressed as TIER.

Government function. In this paper, it can be measured in the proportion of service investment in fixed assets accounted for total investment in fixed assets and expressed as PIFA.

Human resources. In this paper, it can be measured in the number of college students per million and expressed as HR.

\subsection{Model Building}

According to the above variables and multiple linear regression models, this paper quantitative analyzes the development level of the service industry in Guangxi. Construct the model as follows:

$$
\begin{aligned}
& S G D P R_{\mathrm{t}}=\beta_{0}+\beta_{1} P G D P_{t}+\beta_{2} P A D I_{t}+\beta_{3} P D_{t}+\beta_{4} N A R_{t} \\
& +\beta_{5} I G D P R_{t}+\beta_{6} T I E R_{t}+\beta_{7} P I F A_{t}+\beta_{8} H R_{t}+\varepsilon_{t}
\end{aligned}
$$

Among them: $\beta_{0}$ is the constant term, $\beta_{1}, \beta_{2} \cdots \beta_{8}$ are coefficients, $\varepsilon$ is error term.

\section{Empirical Analysis of Influencing Factors}

\subsection{Data Source}

Because there is a big gap in indicators and range before and after the year 2000 statistics, so this paper collects thirteen years' data from 2000 to 2012 in Guangxi for authenticity and comprehensiveness. All data are from the "Guangxi Statistical Yearbook"(2001-2013). Most of the indicators are calculated by using formula with the data from yearbooks. Since the total import \& export that are from the statistical yearbook and their units are dollars, so we change dollar into yuan with the middle price of exchange rate of RMB per year. It is convenient for further calculation.

\subsection{Unit Root Test}

If the time series are not stable and don't have unchanged center trend, so it can occur deviation when we conduct regression and produce significant and well-fitted spurious regression ${ }^{[3]}$. Therefore, this paper conducts unit root test on all variables before doing regression. The most common method is ADF unit root test. We should map each variable sequence first before we conduct unit root test and observe whether there is the intercept and trend or not, then choose one method according to these images. The test results are shown in table 1. 
Table 1. The Result of Unit Root Test

\begin{tabular}{|c|c|c|c|c|c|c|}
\hline variables & $\begin{array}{c}\text { Differe } \\
\text { ntial } \\
\text { times }\end{array}$ & $\begin{array}{c}\text { ADF } \\
\text { values }\end{array}$ & $\begin{array}{c}10 \% \\
\text { level }\end{array}$ & 5\% level & 1\%level & conclusion \\
\hline SGDPR & 0 & -4.07213 & -2.71375 & -3.14492 & -4.12199 & steady \\
\hline PGDP & 2 & -3.80667 & -2.80138 & -3.32096 & -4.58264 & steady \\
\hline PADI & 2 & -2.78857 & -2.74767 & -3.21269 & -4.29707 & steady \\
\hline PD & 1 & -6.97645 & -3.46079 & -4.00815 & -5.29538 & steady \\
\hline NAR & 1 & -3.15713 & -2.74767 & -3.21269 & -4.29707 & steady \\
\hline IGDPR & 1 & -3.51605 & -2.77112 & -3.25980 & -4.42059 & steady \\
\hline TIER & 1 & -3.93896 & -2.74767 & -3.21269 & -4.29707 & steady \\
\hline PIFA & 1 & -4.66086 & -2.72898 & -3.17535 & -4.20005 & steady \\
\hline HR & 1 & -4.97227 & -2.77112 & -3.25980 & -4.42059 & steady \\
\hline
\end{tabular}

Table 1 clearly shows that most variables pass the stationary test at $1 \%$ level and others pass the test at $5 \%$ level. So the data are stationary in the differential form and there doesn't exist spurious regression. Differential times in the table are known as orders. The order of dependent variable SGDPR is zero and less than all independent variables' orders, so we can carry on cointegration analysis.

\subsection{Cointegration Analysis (EG two-step method)}

In order to test whether there exists cointegration relationship between the different variables and examine how these variables impact service industry in the economic fundamentals, so this paper uses EG two-step method.

\subsubsection{Cointegration Regression Estimating}

Table 2. The Result of Cointegration Regression

\begin{tabular}{|c|c|c|c|c|}
\hline Variable & Coefficient & Std. Error & t-Statistic & Prob. \\
\hline C & 1.043499 & 0.568951 & 1.834072 & 0.140561 \\
\hline PGDP & 0.181122 & 0.115278 & 1.571172 & 0.191237 \\
\hline PADI & 0.000007 & 0.000014 & 0.477975 & 0.657616 \\
\hline PD & -0.005263 & 0.003413 & -1.541905 & 0.197956 \\
\hline NAR & 0.848402 & 1.004895 & 0.844269 & 0.446054 \\
\hline R-squared & 0.775480 & \multicolumn{2}{|c|}{ Mean dependent var } & 0.372477 \\
\hline Adjusted R-squared & 0.326440 & \multicolumn{2}{|l}{ S.D. dependent var } & 0.023206 \\
\hline F-statistic & 1.726975 & \multicolumn{2}{|l}{} \\
\hline Prob(F-statistic) & 0.313568 & \multicolumn{4}{l}{} \\
\hline
\end{tabular}

From table 2 we can see that R-squared of cointegration model is 0.78 and it shows a high-fitted degree of this equation. Durbin-Watson stat is 2.24, which indicates that the model does not has autocorrelation. Therefore, the long-term equilibrium relationship among variables is:

$$
\begin{aligned}
& S G D P R_{t}=1.043499+0.181122 P G D P_{t}+0.000007 P A D I_{t} \\
& -0.005263 P D_{t}+0.848402 N A R_{t}-0.372937 I G D P R_{t} \\
& +1.476538 T I E R_{t}+0.692578 P I F A_{t}+0.000892 H R_{t}
\end{aligned}
$$

\subsubsection{Unit Root Test of the Residual Sequence E}

Get residuals of regression equation above. Then we use ADF unit root test to test this residual sequence in order to see if the residual sequence is stable. Result of residual sequence unit root test is shown in Table 3. From the table we can see that the unit root test statistic is -4.279319 , which is significantly less than 1\% level's critical value(-4.200055). Therefore, we should reject the null 
hypothesis at the $1 \%$ significant level and the residual sequence $\mathrm{E}$ has no unit root. It indicates that there exists a cointegration and long-term equilibrium relationship among the above variables.

Table 3. The Result of Residual Sequence Unit Root Test

\begin{tabular}{|c|c|c|c|}
\hline \multicolumn{4}{|c|}{$\begin{array}{l}\text { Null Hypothesis: E has a unit root } \\
\text { Exogenous: Constant } \\
\text { Lag Length: } 1 \text { (Automatic based on SIC, MAXLAG=2) }\end{array}$} \\
\hline+2 & 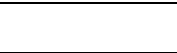 & t-Statistic & Prob.* \\
\hline \multicolumn{2}{|c|}{ Augmented Dickey-Fuller test statistic } & -4.279319 & 0.008857 \\
\hline \multirow[t]{3}{*}{ Test critical values: } & $1 \%$ level & -4.200055 & \\
\hline & $5 \%$ level & -3.175352 & \\
\hline & $10 \%$ level & -2.728985 & \\
\hline
\end{tabular}

\section{Analysis of Empirical Results}

The proportion of service added value accounted for the GDP increases one percentage point can make per capita GDP increase 0.18 percentage points. Income level's coefficient is very small because this data is very large. Urbanization level has an obvious influence on service industry and the regression coefficient is 0.85 , which indicates that urbanization can effectively promote the development of service industry. In this paper, we find that the development of industry and service industry is negative correlated through empirical analysis. Openness has an obvious influence on service industry and the regression coefficient is up to 1.48, which indicates that openness plays a significant positive impact on the development of service industry. Government function's regression coefficient is 0.69 , which shows that government plays an important role in the development of service industry. Effect of human resources on the service industry is not obvious, but it has a positive promoting effect.

\section{Acknowledgement}

This research was financially supported by the Foundation of Guangxi Educational Committee (Grant No: SK13ZD030)

\section{References}

[1] JIANG Xiao-juan, LI Hui: Service Industry and China’s Economy: Correlation and Potential of Faster Growth. J. Economic Research, Vol.11, pp. 4-14, 2004

[2] CHEN Kai: Analysis of the Factors Affecting the Changes in the Internal Structure of China Service Industry. J. Finance \& Trade Economics., Vol. 10, pp. 53-58 ， 2006

[3] LI Jiang-fan: Strategic Position and Development Direction of Tertiary Industry in China. J. Finance \& Trade Economics. Vol. 1, pp. 65-74, 2004

[4] GU Ying-wei, FU Xin-xia: A Study on the Influencing Factors of the Competitiveness of Modern Service Industry in Liaoning Province. J. China Market, Vol. 33, pp. 83-86 ， 2013

[5] LI Liang-cheng, YANG Guo-dong. "Research on the Index system and the Evaluation of the Competitiveness of Innovative Talents in Guangdong Province” [J].Science \& Technology Progress and Policy, Vol.19, pp. 130-135, 2012 